\title{
Comunicação, Ciência, Tecnologia e Conhecimento: percepção pública de estudantes do ensino médio em escola da zona rural, Pernambuco-BRASIL
}

Comunicación, Ciencia, Tecnología y Conocimiento: percepción pública de estudiantes de enseñanza media en escuela de la zona rural, Pernambuco-BRASIL

Communication, Science, Technology and Knowledge: public perception of high school students in rural school, Pernambuco-Brazil

Felipe de Carvalho Souza1

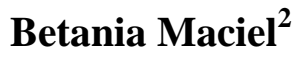

\begin{abstract}
Resumo
Propiciar uma reflexão capaz de abarcar elementos da teoria social na construção das identidades, possibilitando compreender como se dá a construção do conhecimento, resultante do letramento científico na formação contemporânea, nos principais processos de estratificação de atores na sociedade moderna, identificando quais as principais estratégias de comunicação utilizadas e os impactos das Tecnologias de Informação e Comunicação no cotidiano da população jovem no meio rural, sobretudo no que condiciona a percepção pública sobre Ciência e Tecnologia. A pesquisa de campo caracterizou-se pelas investigações em que, além da pesquisa bibliográfica e/ou documental, elaborou-se a coleta de dados junto a alunos e professores, com o recurso de diferentes tipos de pesquisa ex-post-facto, pesquisa-ação e a pesquisa participante. Constatou-se que as tecnologias de informação e comunicação disponibilizam grande volume e diversidade de informações que implicam o desenvolvimento de habilidades e a reconstrução permanente de conhecimentos que tornam a seleção e o tratamento das informações eficientes e objetivos. Com este debate relacionado a prática e desdobramento da comunicação científica na escola, constatou-se que a atitude do grupo pesquisado em relação à ciência e à tecnologia é positiva e otimista. Há uma expectativa de que a ciência seja um fator de transformação para melhorar a qualidade de vida das pessoas. Isso tem a ver com a percepção da ciência como um instrumento que gera resultados aplicáveis às suas vidas e capaz de solucionar problemas, como por exemplo, na área de saúde e meio ambiente.
\end{abstract}

Palavras-Chave: Ciência; Juventude; Percepção Pública; Tecnologia; Ensino Médio.

\section{Resumen}

Propiciar una reflexión capaz de abarcar elementos de la teoría social en la construcción de las identidades, posibilitando comprender cómo se da la construcción del conocimiento, resultante del letra científico en la formación contemporánea, en los principales procesos de estratificación de actores en la sociedad moderna, identificando cuáles son las principales estrategias de estratificación y las repercusiones de las Tecnologías de Información y Comunicación en el cotidiano de la población joven en el medio rural, sobre todo en lo que condiciona la percepción pública sobre Ciencia y Tecnología. La investigación de campo se caracterizó por las investigaciones en que, además de la investigación bibliográfica y / o documental, se elaboró la recolección de

1 Mestre em Extensão rural e desenvolvimento local, POSMEX/UFRPE, Recife., Pernambuco-BRASIL; E-mail: souzafelipe@msn.com.

2 Doutora em Comunicação Social pela Universidade Metodista de São Paulo. Professora da Faculdade Integrada de Pernambuco - FACIPE. E-mail: betaniamaciel@gmail.com. 
datos junto a alumnos y profesores, con el recurso de diferentes tipos de investigación ex post-facto, y la investigación participante. Se constató que las tecnologías de información y comunicación ofrecen gran volumen y diversidad de informaciones que implican el desarrollo de habilidades y la reconstrucción permanente de conocimientos que hacen la selección y el tratamiento de las informaciones eficientes y objetivos. Con este debate relacionado a la práctica y desdoblamiento de la comunicación científica en la escuela, se constató que la actitud del grupo investigado en relación a la ciencia ya la tecnología es positiva y optimista. Hay una expectativa de que la ciencia sea un factor de transformación para mejorar la calidad de vida de las personas. Esto tiene que ver con la percepción de la ciencia como un instrumento que genera resultados aplicables a sus vidas y capaz de solucionar problemas, como por ejemplo, en el área de salud y medio ambiente.

Palabras claves: Ciencia; Juventud; Percepción pública; Tecnología; Enseñanza Media.

\begin{abstract}
To foster a reflection capable of encompassing elements of social theory in the construction of identities, making it possible to understand how the construction of knowledge occurs, resulting from the scientific letter in contemporary formation, in the main processes of stratification of actors in modern society, identifying the main strategies of stratification and the repercussions of Information and Communication Technologies on the daily life of the young population in rural areas, especially in what conditions the public perception of Science and Technology. Field research was characterized by research in which, in addition to bibliographic and / or documentary research, data collection was developed together with students and professors, using different types of ex post-facto research, and the participant research. It was found that information and communication technologies offer a large volume and diversity of information that involves the development of skills and the permanent reconstruction of knowledge that makes the selection and processing of information efficient and objective. With this debate related to the practice and unfolding of scientific communication in the school, it was found that the attitude of the group researched in relation to science and technology is positive and optimistic. There is an expectation that science is a factor of transformation to improve the quality of life of people. This has to do with the perception of science as an instrument that generates results applicable to their lives and capable of solving problems, such as, for example, in the area of health and the environment.
\end{abstract}

Keywords: Science; Youth; Public perception; Technology; Secondary education.

\title{
1. Introdução
}

Buscamos compreender de que forma se estrutura o conhecimento advindo da informação, por sua vez resultante de processos de comunicação contribuem para uma noção aprofundada ou superficial do saber científico, entre jovens alunos de uma escola municipal da Região Metropolitana do Recife. Valores que perpassam a percepção dos direitos, sobretudo o direito a comunicação e formação cidadã a partir das atividades desenvolvidas na Escola Municipal Bola na Rede. A partir deste estudo, pretende-se adentrar nos debates relacionados as práticas e desdobramentos da comunicação comunitária no bairro, a fim de investigar a produção e recepção dos discursos no que diz a respeito de sua percepção pública quanto a Ciência e Tecnologia. Buscou-se entender a luz das teorias sociais, do desenvolvimento e sobretudo da comunicação, de que forma os usos e apropriações dessas tecnologias de informação e comunicação por parte dos jovens que compõem o corpo discente da escola podem contribuir para o desenvolvimento local.

Muitas vezes o conhecimento globalizado se põe em detrimento do conhecimento local, favorecendo uma indústria midiática pouco nos induza possibilidade de análise de troca 
de experiências que condicionem o desenvolvimento humano nas mais diversas formas. A ausência de autonomia e os diálogos possíveis desdobrados na construção do saber precisam ser explorados.

A partir da percepção de que todo conteúdo se transforma em informação, mas nem toda a informação resulta em comunicação ou que nem toda comunicação se transforma em conhecimento, nos propomos então a discutir de que forma os processos de comunicação se transformam em informação, de que forma a informação se traduz em conhecimento e paralelo a isto, como o uso das Tecnologias de Informação e Comunicação, em meio a um contexto de desigualdade social condiciona o letramento científico.

$A$ etapa empírica da pesquisa consta do contato com o material produzido pelos alunos da Escola Municipal Bola na Rede durante o ano de 2016. A escola desenvolve atividades a fim de ampliar a jornada escolar e contribuir de forma significativa na organização curricular através da educação em tempo integral. Em linhas gerais, as atividades se dividem em dois campos específicos, sendo o primeiro deles se referente a escolarização, ao processo de aprendizagem no contexto escolar comum. O segundo é o de atividades, onde pretende-se pesquisas as o contexto de complementar, que remete a atividades de livre escolha por parte dos alunos que complemente o currículo de escolarização obrigatório. De forma que, através do exercício a comunicação o perfil de quebra de paradigmas, fundamentados em perspectivas que se distanciam dos modelos formais de educação, ainda que executadas no mesmo ambiente.

Nos contextos atuais a necessidade de incluir o olhar dos pesquisados se faz mais do que necessária, sobretudo quando se contextualiza neste aspecto a construção de novos saberes e ressignificação de conceitos, de forma a inserir a multiplicidade de atores sociais como peça chave na construção denovos dogmas não só entre os estabelecidos e os outsiders, mas mais especificamente entre quem observa e quem é observado. Portanto, na segunda etapa realizamos entrevistas e grupos focais com os jovens que produziram atividades relativas à Ciência e Tecnologia, identificando seus níveis de percepção sobre a temática. Os grupos focais, possibilitaram a proximidade entre pesquisador e pesquisado, a fim de estabelecer um padrão de interação que possibilitou ouvir mais o que os jovens tem a dizer e permitir que em meio a seu próprio discurso estes se questionassem. Assim como diz Bourdieu (1983), o resultado de produções culturais, materiais e simbólicas pertence ao conjunto da sociedade e por ela mesma favorece a interpretação dos processos históricos de desenvolvimento. 
Por fim, na análise de dados, se desenvolveu o cruzamento de informações e construção de categorias teóricas para o agrupamento de comportamentos. Tomando-se como aporte teórico autores que possibilitem a compreensão dentro das dinâmicas contemporâneas o jovem enquanto ator social, bem com as perspectivas correspondentes a necessidades e expectativas. Como este jovem se encontra no mundo, como se representa e como se identifica? Para entender estas mudanças estruturais depensamento, nos âmbitos coletivos e individuais, esta análise partirá de autores como Manuel Castells e Pierre Lévy, Néstor Garcia Canclini, Stuart Hall, Norbert Elias, entreoutros, condicionando aos desdobramentos a perspectiva contemporânea da chamada sociedade do conhecimento.

O trabalho desenvolve-se em três eixos principais, de forma a culminar numa análise social quanto a percepção da juventude rural inserida no contexto da Escola Municipal Bola $\mathrm{Na}$ Rede, sobre as práticas de ciência e tecnologia através de uma política comunicacional específica. Num segundo momento, busca-se uma análise crítica da comunicação e sua relação com práticas de mobilização social, desde sua interação com as massas e suas matrizes culturais na América Latina, fazendo um apanhado histórico e debatendo sobreas metodologias alternativas de produzir comunicação, da postura da mídia radical e do contraponto feito por novas propostas de comunicação no meio rural. Por fim, oreferencia teórico culmina na percepção das tecnologias de informação e comunicação no que tange seu papel na sociedade da informação para compreendermos o processo de exclusão digital no meio rural.

Para além da percepção da juventude sobre Ciência e Tecnologia, o estudo propõe entender o jovem em meio a um processo de letramento científico, enquanto um indivíduo portador de direitos, ator político e cidadão, e inicia-se considerando de forma bastante superficial que entre os jovens, o que é dito e absorvido pela veiculação midiática condiciona a sustentação de valores, de forma a se evidenciar enquanto influente, numa perspectiva de reconfiguração social. Busca-se entender os alunos da Escola Municipal Bola na Rede, enquanto atores sociais, sujeitos históricos de ações transformadoras em meio aos seus valores e formas de estar no mundo através das atividades realizadas por estes no espaço escolar, bem como instrumentos promotores de mediação entre o mundo da vida e a esfera pública e política, construindo novas formas de reprodução social e cultural. Os processos de Ensino das Ciências, em seus mais distintos níveis torna-se indispensável ferramenta para formação dos jovens, se passarmos a considerar que esta possibilita, dentro de uma perspectiva coletiva a construção da liberdade de expressão através da reflexão crítica através do processo de construção e recepção de informações. Tal processo impulsiona o indivíduo a 
desenvolver a capacidade não só de raciocínio, mas também de interpretação de sua realidade social atrelado ao saber científico.

De tal forma, a relevância deste estudo se constitui visando contribuições teóricas, práticas e metodológicas que possam vir a se desenvolver quanto a produção deconhecimento sobre a influência das NTICs no que compete também a um aprofundamento de estruturação da Percepção Pública de Ciência entre os jovens. Consideramos assim, que esta proposta poderá contribuir de forma a oferecer subsídio a futuras análises nas diversas áreas da comunicação que contemplem significados sociais para além do modelo hegemônico de produção de conhecimento. Todo envolvimento referente ao pesquisador e condicionado a pesquisa estão para além das percepções adquiridas dentro e fora da academia. A experiência em campo condiciona uma militância por direitos relacionados a comunicação de forma a intensificar o desejo quanto a produção e reprodução de conhecimento sobre a temática.

\section{Processos de Comunicação e Informação numa perspectiva democrática}

Nesta pesquisa nos propomos pensar no direito à comunicação como instrumento do resgate a comunicação, primariamente desenvolvida nos meios sociais. De tal forma, buscamos pensar uma comunicação que não se esgota em si, mas que se multiplica nas coletividades do cotidiano. Buscaremos aqui entender como se solidifica uma comunicação entendida como popular que considera as transformações engendradas pelo avanço do capitalismo no mundo, de perspectivas centrais a periféricas, moldando-se às distintas estratificações sociais ocasionadas por este sistema econômico.

Nos pautamos a pensar a comunicação como algo gestado no interior da organização dos diversos movimentos sociais e populares, que aparentam estar em ascensão desde o declínio do regime militar até os dias atuais. Comunicação esta, que evidencia o surgimento de novos personagens e com eles novas dinâmicas sociais. A proposta desta dissertação neste primeiro capítulo está em analisar como se dão os processos de produção de uma comunicação participativa, a fim de entendermos dentro deste processo comunicacional auxiliado por Novas Tecnologias de Informação e Comunicação, como se dá a percepção pública de Ciência e Tecnologia entre os jovens e qual a contribuição desta percepção para o desenvolvimento local da região.

Lutas em prol da vida, da justiça social e da pessoa humana estão presentes na construção sócio-histórica da maioria das civilizações contemporâneas. No Brasil, este exemplo não é diferente. Do Quilombo dos Palmares, das Greves de 1917, das "Diretas Já" até as manifestações políticas e contra-políticas dos dias atuais, tornam-se evidentes 
aconstante e dinâmica (re)constituição de novos valores para sociedade. "O homem tem como essência a potencialidade de ser sujeito da história. Alienando-se, ele perverte osseus valores próprios, transformando-se em objeto. Nessas condições, ele se deforma, seembrutece, se desumaniza”. (PERUZZO, 1998, p.26)

O papel da comunicação está em interpor-se nas relações sociais e vai assumir feições diferenciadas de acordo com cada momento histórico. Dentro das mobilizações sociais a comunicação se dá - ou deveria se dar - como instrumento de estímulo a luta e a vontade de mudanças. Para afirmar isto, vamos considerar que a comunicação, enquanto instrumento de mobilização social, carece de uma evolução mais satisfatória. Ou seja, uma comunicação de maior autonomia.

Nos propomos primariamente a entender como se articulam aqueles que dela se utilizam. Movimentos sociais, coletivos, populares, urbanos e rurais se agrupam onde equando surgem os conflitos econômicos, sociais, ideológicos, religiosos e onde há motivação em por fim desigualdades culturais e sobretudo mediação e repressão por partede esferas superiores, como o Estado.

Numa sociedade onde há mais autoritarismo e delegação de poder do que o compartilhamento do controle e co-responsabilidade na solução de problemas, estamos sempre a espera de que o outro, resolva tudo. Este outro, por muitas vezes toma o papel de protagonista que deveria ser nosso. Culturalmente parece ocorrer em todas as instâncias de mobilização social e de participação política.

Partindo de uma perspectiva gramsciana, a sociedade civil representa o momento ativo e positivo do desenvolvimento histórico. Para Gramsci, a perspectiva é de que a sociedade civil é o mundo da ideologia, da hegemonia, da cultura ou da "direção intelectual e moral", que situa-se junto a sociedade política (Estado), no nível da superestrutura. Ou seja, de um lado a sociedade civil, do outro a sociedade política (hegemônica). O grupo dominante, por seus intelectuais orgânicos, age no seio da superestrutura, orientando a vida social com base no consenso da população ou então na coerção, por meio do aparato de repressão estatal que assegura legalmente a disciplinados grupos que discordam.

Em decorrência disto, surgem novas estruturas sociais que caracterizam movimentos limitados e transitórios, mas que põem em prática um modelo de desenvolvimento que vem das camadas sociais de base para cima, bottom-up, por sua vez preenchendo espaços ainda não ocupados politicamente, espaços onde há ausência do Estado.

A representação política que surge não impede que se expressem dimensões comuns, como o descontentamento com o tipo de desenvolvimento social explicitado nas 
reivindicações por melhores salários, usufruir de bens de consumo coletivo e individual, infraestrutura, etc. Ao tornarem transparente a reivindicação pela democratização do acesso a ela, os movimentos coletivos estão denunciando a existência de desigualdades e tornando explícito um conflito de interno de classes. (PERUZZO, 1998, p. 57).

É importante salientar também que não há um antagonismo ferrenho em relação ao Estado, de forma a negar tudo que dele provém. Porém, grande parte dos movimentos sociais articulados, lutam por autonomia de forma a estarem inclusos também nos planos e programas públicos que sejam de interesse social. Não se trata, portanto, de fazer oposição ao estado, mas sim de ampliar seu processo de participação dentro dele. A luta não é pelo poder, mas para compartilhar o poder.

Entende-se, de tal forma, o surgimento de novos valores coletivos que se fundamentam na igualdade e no reconhecimento do outro, das carências e problemas em comum, de acordo com as necessidades e demandas locais. A compreensão dos direitos se faz presente, de modo que uma carência individual possa vir a contribuir a uma ação conjunta. Isto se estabelece a partir do momento em que há uma forma direta de participação no poder, ainda que apenas por meio do sufrágio universal, a partilha da experiência de igualdade e de atuação nos processos sociais estimula a extensão das formas de poder.

Pensando na conjuntura atual, autores como Bobbio (1986) dizem que apesar de haver de fato uma ocupação de novos espaços até então dominados por organizações hierárquicas e/ou burocráticas, não há necessariamente um novo tipo de democracia em voga. Se pensarmos que nas democracias avançadas o cidadão atuante e participativo politicamente se percebe num âmbito mais amplo, da sociedade em seu conjunto, entendemos que não há participação política que não esteja condicionada por aquilo que acontece na sociedade civil. Pensando na conjuntura nacional atual, Bobbio estaria certo: Toda nossa participação política se resume ao individualismo, falta de conhecimento crítico, capacidade argumentativa e sobretudo de articulação social. Portanto, não há democratização política sem democratização social. Bem como, não há democratização social sem uma democratização efusiva dos meios de comunicação.

Ao se referir às perspectivas futuras da democracia, Bobbio (1986) afirma que o termo democracia parece não se encontrar de outra forma senão atrelado ao ideal de transformação, em toda e qualquer sociedade. Foram muitas as democracias pós-Primeira Guerra Mundial que se abateram a ditaduras na Europa, no pós-Segunda Guerra o mesmo aconteceu com os países Sul-americanos. Hoje, no pós-ditadura, ainda vivemos restrições democráticas tais 
como o controle e monopólio dos meios de comunicação, por parte de grandes empresas, que por sua vez ditam o que é tendência e, como se não bastasse, também o que é necessidade.

\subsection{Panorama Geral da Ciência e Tecnologia no Brasil}

No ano de 1990 foi criada através das Organizações das Nações Unidas para Educação, a Ciência e Cultura (UNESCO) a chamada Rede de Popularização da Ciência e Tecnologia da América Latina e Caribe, conhecida como Red-Pop. Como o próprio nome diz esta tem como principal objetivo o fortalecimento e ativa cooperação entre os programas de popularização e divulgação científica e tecnológica na América Latina e Caribe. ${ }^{3}$

O apoio a grupos, programas e centros para o desenvolvimento e profissionalização da C\&T, sobretudo no que se refere à formação e capacitação profissional, juntamente com o apoio a estudos, replicações de dados e investigações no campo além da assessoria a grupos em processo de formação caracterizam algumas das atividades desenvolvidas pela Red-Pop nas últimas quase três décadas de funcionamento.

No ano de 2013, em uma das reuniões da Red-Pop, estabeleceu-se uma declaração a fim de guiar suas ações nos próximos anos, onde os membros honorários e titulares da rede se comprometeram a lutar e contribuir no que se refere a seis ações para o avanço da Ciência e Tecnologia como ferramenta de apropriação social. Entre estas ações identifica-se a intenção de impulsionar e consolidar políticas públicas a níveis nacionais e locais que possam fortalecer ações de popularização através de incentivos, o reconhecimento da divulgação da ciência enquanto uma profissão e como atividade relevante, a promoção e intensificação do intercâmbio entre os países latinos e caribenhos e por fim, mas não menos importante, reconhecer as origens multiculturais da ciência, entendendo esta como parte da cultura. As culturas e conhecimentos locais devem ser considerados nas atividades de popularização da ciência.

Nos últimos anos o governo brasileiro vem promovendo um grande esforço a fim de estabelecer uma política de difusão e popularização da ciência, a medida em que esta corresponda às crescentes demandas da população. Atualmente o Ministério correspondente por tais ações é o da Ciência, Tecnologia e Inovações e Comunicação, fruto de uma reformulação ministerial proposta pelo governo do presidente Michel Temer, que incorporou a Ciência e Tecnologia o ministério da Comunicação.

\footnotetext{
${ }^{3}$ Disponível para acesso através do link: http://www.redpop.org/wp-content/uploads/2015/06/Estatutos-RedPOP2015b.pdf (Acesso em 20 de Junho de 2017)
} 
O ministério que hoje parece mais um remendo de diversos setores públicos, contou com a reformulação e extinção de pastas. Hoje se organizando através de oito áreas temáticas. Basicamente voltadas para o desenvolvimento de ações de C\&T para o mercado e não necessariamente para o desenvolvimento humano.

Estas giram em torno de basicamente três eixos, como podemos ver na tabela abaixo:

\begin{tabular}{|c|c|}
$\begin{array}{c}\text { CT\&I para a } \\
\text { Competitividade } \\
\text { Brasileira }\end{array}$ & $\begin{array}{c}\text { Onde concentram-se atividades relativas ao desenvolvimento } \\
\text { aeroespacial, agropecuário, biotecnológico, energia, fármacos e saúde, } \\
\text { nuclear, petróleo e gás, nanotecnologia, tecnologias da informação e } \\
\text { comunicação. }\end{array}$ \\
\hline $\begin{array}{c}\text { CT\&I para } \\
\text { Recursos Naturais }\end{array}$ & $\begin{array}{c}\text { Onde concentram-se atividades relativas ao desenvolvimento da } \\
\text { biodiversidade, biotecnologia marinha, desastres naturais, meteorologia, } \\
\text { climatologia e hidrologia, mudanças climáticas, recursos hídricos e } \\
\text { minerais. }\end{array}$ \\
\hline $\begin{array}{c}\text { CT\&I para o } \\
\text { Desenvolvimento }\end{array}$ & $\begin{array}{c}\text { Onde concentram-se atividades relativas ao desenvolvimento da } \\
\text { inclusão digital, social e produtiva, tecnologias sociais e assistivas e, } \\
\text { por fim, popularização da CT\&I e Melhoria do Ensino de Ciências. }\end{array}$ \\
& \\
\hline
\end{tabular}

Fonte: Portal do Ministério da Ciência, Tecnologia, Inovação e Comunicação

Em paralelo a estas ações, o inchaço ministerial também compreende a coordenação dos programas de Telecomunicações e de Radiodifusão, essenciais ao desenvolvimento das atividades de Ciência e Tecnologia, sobretudo no que corresponde a divulgação científica. Entre os eixos trabalhados nas subdivisões ministeriais, destacam-se o Programa Nacional de Banda Larga (PNBL), a implementação da TV Digital, a migração das rádios AM, a implementação da Rádio Digital, a acessibilidade na TV aberta, a radiodifusão educativa e a radiodifusão comunitária.

Um ponto importante na consolidação da Divulgação Científica no Brasil foram as Conferências Nacionais de CT\&I, que iniciaram em 1985, idealizadas por Renato Archer que mais tarde veio a se tornar o primeiro Ministro de Ciência e Tecnologia do país. Posteriormente houveram mais três conferências, uma no final do governo de Fernando Henrique Cardoso, em setembro de 2001 e mais duas durante o governo de Luís Inácio da Silva, em agosto de 2005 e maio de 2010.

Oriundas dessas conferências nasceram parte da política que criou-se os museus de ciência em diversas regiões brasileiras, bem como ampliou-se o incentivo e realização das 
olimpíadas de Ciências, Matemática, História e outras disciplinas, juntamente a cursos visando a formação de professores de Ciências nas escolas de Ensino Básico, Fundamental e Médio, além de diversas ações promovidas por veículos de comunicação formal e não formal.

A partir de 2003, já durante o Governo Lula, foi criada a Secretaria de Ciência, Tecnologia e Inclusão Social - SECIS, extinta pelo novo governo e vinculada ao reformulado Ministério da Ciência e Tecnologia. A SECIS deu origem ao Departamento de Popularização e Difusão de Ciência e Tecnologia - DEPDI, responsável portanto no que se referia a formulação de políticas e implementações de programas na área, colaboração da melhoria do Ensino de Ciências junto ao Ministério da Educação e com as Secretarias Estaduais de Educação, apoio a museus de ciências e organização de eventos de difusão científica, sobretudo no que corresponde a organização da Semana Nacional de Ciência e Tecnologia, no ano de 2005. No mesmo ano de 2005, durante a terceira conferência a DEPDI apresentou o "Esboço de uma política pública para a popularização da C\&T no Brasil" com o levantamento de aspectos centrais relacionais a situação da divulgação científica no país.

A IV Conferência Nacional de CT\&I para o Desenvolvimento Sustentável aconteceu em 2010, data em que foi publicado o chamado Livro Azul, onde por fim estabeleceram-se as principais diretrizes para a consolidação de uma política nacional de CT\&I. Neste documento, encontra-se o POP CIÊNCIA 2022 - Programa Nacional de Popularização e Apropriação Social da CT\&I 2011-2022, contemplando o envolvimento de universidades, instituições de pesquisa e organismos por parte do Estado e da sociedade civil. Segundo consta, a proposta gira em torno de

[...] Valorizar as atividades de popularização da C\&T e promover a formação qualificada de jornalistas científicos, comunicadores da ciência e assessores de comunicação, bem como a capacitação de cientistas, professores e estudantes para a comunicação pública da ciência. (BRASIL. Ministério da Ciência e Tecnologia MCT, 2010, p. 92)

Tais medidas, ministérios e secretarias mantiveram-se durante o governo Dilma Rousseff, até seu impeachment no ano de 2016. Durante a reformulação do governo Michel Temer e consequentemente dos ministérios, a SECIS foi dissolvida nas secretarias vigentes, que hoje são: Secretaria de Radiodifusão, Secretaria de Políticas e Programas de Desenvolvimento, Secretaria de Desenvolvimento Tecnológico e Inovação, Secretaria de Telecomunicações e Secretaria de Política e Informática.

A referente medida implicou em cortes orçamentais que consequentemente afetam os programas e propostas desenvolvidos ao longo de anos. O atual ministério, através da 
Comissão de Ciência, Tecnologia, Inovação, Comunicação e Informática (CCT) sobre o desenvolvimento tecnológico estabelece um corte no orçamento do Ministério da Ciência, Tecnologia, Inovação e Comunicações para 2017, em virtude da impossibilidade de cumprimento da meta de déficit primário no orçamento para 2017. A restrição atingiu $44 \%$ do já restrito orçamento para 2017, fazendo com que este seja o menor valor que a área vai dispor em 12 anos. Ou seja, considerando a soma de outro ministério ao da Ciência e Tecnologia, este valor é ainda mais impactante, praticamente regredindo ao ponto em que começou a de fato se desenvolver. ${ }^{4}$

Em linhas gerais podemos dizer que o governo brasileiro hoje, ainda busca promover uma política de difusão e popularização da ciência que por sua vez tenta atender às demandas da população, a fim de tornar mais curta a distância entre a ciência e a vida cotidiana. A divulgação científica, por sua vez, continuou a incorporar a agenda governamental integrados políticas públicas previstas nas Conferências Nacionais de Ciência, Tecnologia e Inovação.

[...] Houve um crescimento acentuado dos espaços científico-culturais [...], sua organização em rede e a realização de muitas atividades de divulgação científica. Mas essas iniciativas estão longe de conduzir à popularização da C\&T e à sua apropriação social em níveis adequados. (BRASIL. Ministério da Ciência e Tecnologia - MCT, 2010, p. 89-90)

O conselho Nacional de Desenvolvimento Científico e Tecnológico (CNPq) incluiu a partir de 2011, novos critérios de avaliação de pesquisadores através da plataforma Lattes, sendo estes a inovação dos projetos de pesquisa a divulgação e educação científica, avaliando também se o pesquisador divulga suas pesquisas através de outros meios como blogs e mídia, além da participação palestras e feiras científicas. Um dado interessante estabelecidos nos relatórios de concessão científica do CNPq é da sugestão para que o pesquisador escreva em linguagem clara, para não especialistas, ao menos a justificativa do seu estudo e os objetivos alcançados. Isto pode entender-se como uma possibilidade do incremento correspondente ao interesse por opinião pública relacionado a temas científicos-tecnológicos.

[...] No Brasil, as inovações sociais são inibidas por fragilidades locais em infraestrutura, escassez de pessoal qualificado, a grande burocracia e a pequena tradição das instituições universitárias e de pesquisa em atuar nessa área, entre outros obstáculos que restringem o uso da CT\&I para o desenvolvimento social. (BRASIL. Ministério da Ciência e Tecnologia - MCT, 2010, p. 89-90)

\footnotetext{
${ }^{4}$ Documento disponível para acesso em: http://www12.senado.leg.br/noticias/materias/2017/04/19/corte-noorcamento-da-ciencia-e-tecnologia-e-criticado-em-audiencia (Acesso em 19/Abril/2017)
} 
O governo brasileiro já demonstra interesse por mapear a opinião pública sobre temas ligados a ciência desde 1987, porém só vindo a desenvolver efetivas pesquisas nos anos de 2006 e 2010, através do CNPq com colaboração da UNESCO. Na pesquisa "Percepção Pública da Ciência e Tecnologia no Brasil" foi realizada uma mostra de mais de 2000 entrevistas em várias regiões do país. O levantamento feito pela pesquisa essencialmente aponta a institucionalização das atividades de CT\&I noBrasil, através de ações de aproximação da sociedade por meio das Conferências Nacionais de Ciência e Tecnologia, bem como os desdobramentos provenientes dela. Porém, aponta que trata-se de uma perspectiva superficial, uma vez que o cenário da formação da cultura científica brasileira ainda é limitado, onde poucos dispõem do acesso à educação científica e informação de qualidade sobre CT\&I.

Pensar em Comunicação Científica e suas implicações na Educação para Ciência no contexto da difusão científica é pensar também na amplitude em que se encontra o conceito de cultura, diante de uma perspectiva concebida como multidisciplinar e transversal. O termo Cultura, em especial a cultura científica tem relações diretas com as práticas sociais, tradições linguísticas, processo de constituição de identidades e de comunidades, fazendo com que a relação entre a elaboração científica esteja em parte também condicionada a contextos socioculturais. Segundo Vogt (2006, p. 25)

[...] a expressão cultura científica tem a vantagem de englobar tudo isso e conter ainda, me seu campo de significações, a idéia de que o processo que envolve o desenvolvimento científico é um processo cultural, quer seja considerado do ponto de vista de sua produção, de sua difusão entre pares, ou na dinâmica social do ensino e da educação, ou ainda, do ponto de vista de sua divulgação em sociedade, como todo, para o estabelecimento das relações crítica necessárias entre o cidadão e os valores culturais de seu tempo e sua história.

No Brasil, o surgimento de uma cultura científica desenvolve aspectos importantes a serem avaliados. Um deles é a construção do saber científico em conjunto com os novos meios comunicacionais, de forma a dinamizar as atividades e gerar diálogos entre a pesquisa, aqueles que a fomentam e o público receptor. Não se trata apenas de divulgar a ciência, mas sim de fazer com que o conteúdo divulgado provoque uma reflexão, mesmo que mínimo sobre o uso social desta.

A cultura científica promove uma contribuição no que se refere ao conhecimento, como também, das condições sociopolíticas, econômicas, culturais e históricas da produção do conhecimento científico. Para sua consolidação a importância de sua divulgação é processo essencial, considerando isto para bem além do meio científico. 
Para Chauí (1995) existem três concepções de Ciência - a racionalista, a construtivista e a empirista, deve-se perceber as transformações de ambas diante de um contexto histórico. Segundo a autora,

[...] A ciência distingue-se do senso comum porque este é uma opinião baseada em hábitos, preconceitos, tradições cristalizadas, enquanto a primeira baseia-se em pesquisas, investigações metódicas e estigmáticas e na exigência de que as teorias sejam inteiramente coerentes e digam a verdade sobre a realidade.

Portanto, a ciência se constitui como elemento essencial para o desenvolvimento de uma sociedade, uma vez que mesma promove transformações ligadas ao processo de inovação. Entende-se que a ciência como cultura é uma ciência contextualizada de forma social e tecnológica, que para operar requer uma base educacional científica que possa compreender suas aplicações através de contextos específicos, relacionados a suas demandas. Considera-se então, que a difusão de ciência engloba todos os processos aplicados a veiculação de informações científicas e tecnológicas, ampliando também seu conceito de forma a interagir com diversas práticas condicionadas a uma infinitude de cenários sociais, instituições e atores.

A abordagem quanto a difusão científica perpassa a divulgação da mesma, que começa a fazer parte do cotidiano das pessoas. $\mathrm{Na}$ contemporaneidade, é necessário que esta divulgação ultrapasse o cenário acadêmico. Tudo aquilo ligado a CT\&I deve chegar às mais distintas camadas sociais de forma objetiva, possibilitando uma maior compreensão das pessoas. De tal forma, os meios de comunicação tem papel fundamental para aproximar o público dos resultados e compreensão das pesquisas.

Os processos de comunicação, sobretudo os estabelecidos nas camadas populares nos dias atuais, em face às novas tecnologias presentes, propiciam o recondicionamento do papel entre quem emite e quem recebe a informação. Isto faz com que o ator-rede esteja também se aproximando a ideia de tornar a ciência algo próximo cultural e socialmente de si. Sendo assim, a apropriação do processo científico torna-se um processo ativo e constante. A ciência como cultura é uma ciência em contexto, um meio de promover a partilha social do saber.

\subsection{A Percepção Pública da Ciência e a emergência das TICs na era da informação}

Diante deste contexto, a Percepção Pública de Ciência trata-se de um processo que une os mecanismos de comunicação social e o impacto destes sobre a formação de conceitos relacionados a Ciência e Tecnologia. O desenvolvimento de uma cultura científica se constitui a partir de um padrão de referência orientado por uma diversidade de políticas de difusão e 
comunicação da ciência, organizando-se de forma a determinar o grau de interesse pela informação científico-tecnológica.

Os estudos clássicos quanto a Percepção Pública de Ciência se pautam em três pilares essenciais, sendo estes o nível de interesse pela informação, o acesso às fontes de informação utilizadas, e a valorização ou uso social da C\&T. Entretanto a definição dos significados e componentes que definem os conceitos de percepção pública de ciência permanecem como variáveis abertas. Pautando-se assim um desafio nos dias atuais no que se refere a compreensão da dinâmica referente a interações entre Ciência, Tecnologia e Sociedade. Dito isto, buscaremos neste trabalho referenciar de forma breve alguns modelos de Percepção Pública de

Ciência.

Os estudos sobre Percepção da Ciência tem como início registrado as primeiras enquetes realizadas pela Universidade de Nova York, através da National Association of Science Writers, tendo seu uso sistemático na década de 1970, pela Nacional Science Foundation. Porém estas pesquisas eram meramente quantitativas, apenas consolidando indicadores e carentes de reflexão teórica.

Transformações sociais dinâmicas resultam em novos atores e consequentemente novas formas de ver a sociedade, sobretudo no que se trata de relações sociais interpessoais. A tecnologia é principal instrumento destas relações nos dias de hoje, num conceito de sociedade onde a grande maioria dos sujeitos está conectada, possamos assim dizer. Um indivíduo conectado é um indivíduo que passa a manter novas formas de relações interpessoais em consequência do desenvolvimento tecnológico, de forma a integrar de forma cada vez mais intensa as esferas econômicas, sociais, políticas e culturais.

Na esfera política se estabelecem as novas Tecnologias de Informação e Comunicação, conhecidas como TICs. Responsáveis por mudanças como surgimento do Governo Eletrônico, portais governamentais, portais de transparência dos gastos públicos, uso de redes sociais em campanhas eleitorais, entre tantas outras funções. Concomitantemente surgem ainda novos espaços virtuais e formas de participação política, que se consolidam como ferramenta capaz de atingir um grande número número de pessoas em um curto espaço de tempo.

Numa perspectiva econômica, estas TICs são responsáveis pela difusão de novas tecnologias eletrônicas e digitais no âmbito da comunicação e da informação, acarretando uma nova forma de organização da produção, organização do mercado, gestão econômica e consequentemente aumento nas taxas de produtividade e crescimento. Tudo isto aliado ao 
estabelecimento de um mercado virtual, de compras online e possibilidades de serviços e mesmo de acumulação de capital.

Pelo âmbito cultural, as TICs influenciam diretamente através do desenvolvimento da internet e surgimento constante de novos aparatos tecnológicos (computadores, celulares, tablets, smartphones) a estrutura da vida social, condicionando um novo tipo de cultura chamado de "Cibercultura". Cria-se, portanto, uma cultura virtual, modificada através das práticas sociais, atitudes e variáveis de valores relativos a cada sociedade.

Porém, é no âmbito das relações interpessoais e das novas formas de sociabilidade que percebemos uma efetiva mudança condicionada às TICs. Com o surgimento da internet na década de 1990 e posteriormente da criação e consolidação das redes sociais virtuais, as possibilidades de interação social virtual e simbólica ganharam um novo padrão, passando a ser permeadas por aparatos tecnológicos.

Tal mudança surtiu efeito em distintas esferas sociais, dentre elas a de maior destaque nas últimas décadas sendo a Educação. A forma de adquirir e disseminar conhecimento passou a ser ressignificada, bibliotecas e livros físicos passam a existir em formatos digitais, podendo ser facilmente compartilhados e armazenados por meio de dispositivos eletrônicos e até mesmo online através de serviços de "nuvem".

Consultas a enciclopédias, antes volumosas traduzidas em enormes livros, passam a dar lugar a um simples clique em um grande portal de busca. Este modo de saber virtualidade é denominado por Lévy (1999) como "dilúvio de informações”, sendo este um saber fluido, onde o seu principal desafio dado ao volumoso fluxo de informações é o de justamente filtrálas e transformá-las em conhecimento.

Castells (2005) nos diz que a tecnologia não determina a sociedade, uma vez que esta a incorpora. De tal forma, a sociedade também não determina a inovação tecnológica, e sim, utiliza-a. Existe portanto uma utilização dos instrumentos tecnológicos no cotidiano que possibilidade inúmeras modificações significativas como sendo consequência direta da incorporação tecnológica. Castells (2005) chama isto de uma "Sociedade em Rede".

Entendidas como recursos tecnológicos que propiciam um novo modo de se comunicar, as TICs, seja na "era da informação", da "sociedade em rede" ou exemplificadas no conceito de "cibercultura" passam a descrever um fenômeno tecnológico que passou a ter influência direta nas dinâmicas sociais aplicadas a todos os campos da sociedade. A cronologia deste processo de expansão tecnológica é algo a ser notado, bem como seus desdobramentos mediantes a necessidades sociais. 
Naquilo que corresponde às tecnologias, se faz necessário enfatizar que estas perpassam a vida social ao longo de seu processo histórico, bem como no que se refere a criação de novas técnicas para seu uso, modificando assim vida dos seres humanos, desde os primórdios da história. Centenas são as invenções tecnológicas que influenciaram diretamente na ressignificação do saber e mudar o rumo da humanidade. Isto se dá desde o surgimento das primeiras sociedades até mesmo o estabelecimento das mais complexas, envoltas num contexto pós-industrial. Do domínio do fogo, do cultivo da terra, até o crescimento industrial e a exploração espacial. São diversas, portanto, as significações e representações sociais diante destas mudanças.

Cronologicamente, a revolução tecnológica mais diretamente ligada ao que vivenciamos hoje teve sua difusão a partir de novas tecnologias de informação, oriundas da década de 1960, passando a expandir-se de forma imprescindível e veloz. Segundo Castells (1999) entre as décadas 1970 e 1990 o mundo passou a conectar-se através da informação, porém em paralelo com uma difusão intensa, mas desigual.

Em meados dos anos 1970 se dá início ao que muitos consideram como princípio da revolução tecnológica, sobretudo o aspecto informacional, onde se começa a comercialização do microcomputador (LÉVY, 1999). Os computadores pessoais, também conhecido como PCs (abreviação do inglês Personal Computer) começaram ganhar espaço aos poucos. Na década de 1980 em função da expansão comercial dos PCs passa a surgir o termo "letramento por meio do computador" (3). Contudo ainda em contexto informacional, a transformação mais significativa quanto ao uso dos computadores se deu com o advento da Internet, ainda que com transição de dados limitada.

No final da década de 1990, o americano Bernes-Lee criou o que hoje conhecemos como World Wide Web, o "www". Tal plataforma virtual possibilitou que as informações viessem a se tornar universais, ampliando assim as formas de comunicação entre os computadores e melhoramentos no que se refere as pesquisas e formas de acesso a websites. Nascia portanto um novo mundo virtual, mais acessível e dinâmico para o uso comum da sociedade. Porém, este contexto se deu apenas em uma camada social a princípio, relativa aquele que tinham acesso ao um tipo específico de conhecimento para domínio de hardware e software e até mesmo poder aquisitivo para compra de um computador.

Pari passu, desenvolvia-se também a telefonia celular, acompanhando e incorporando o desenvolvimento físico e virtual dos computadores. A cada grande avanço tecnológico específico ampliam-se os efeitos tecnológicos conexos. Concordando assim, com a idéia estabelecida por CASTELLS (1999) de que os aparatos tecnológicos estão conectados por 
processo que propicia a comunicação eletrônica interativa e ininterrupta em tempo real, que se completam independente de suas especificidades.

Novas atividades cotidianas passaram a ser desenvolvidas com a ampliação e o acesso a novos campos virtuais, modificando esferas de interação a partir do uso principalmente da Internet. $\mathrm{O}$ avanço das TICs juntamente com a implementação da internet em forma de rede modificou a gestão de diversas práticas econômicas, financeiras e empresariais, uma vez que estas se ligam a uma nova forma de organização de produção, distribuição e gestão de mercado, na relação entre compra e venda, bem como na administração e cooperação entre indústrias, empresas, etc.

Isso demonstra, por exemplo, a necessidade de adaptação a um novo conjunto de regras no que concerne aos aspectos citados sobretudo quanto ao investimento do capital. As transformações na economia acarretaram a praticidade a qual o mercado necessitava, segundo Castells (2003) as transformações possibilitaram maior interação entre produtores, fornecedores e compradores, através de uma razão pela qual deveria sempre ter havido uma quebra de barreiras, uma vez que o comércio adquiriu caráter global.

Castells, enfatiza que o ressurgimento ou reestruturação da esfera produtiva, no que corresponde à transformações no mundo do trabalho, com a criação de novas formas de atuação, correspondem a o aumento da autonomia. Segundo o autor:

Essa transformação sociotécnica permeia o sistema econômico em sua totalidade, e afeta todos os processos de criação, de troca e de distribuição de valor. Assim, capital e trabalho, os componentes-chave de todos os processos de negócios, são modificados em suas características, bem como no modo como operam (CASTELLS, 2003, p.57).

As transformações advindas da implementação de TICs passaram a enquadrar-se em uma nova operacionalização dos negócios, do trabalho e também do capital. Tornando-se assim um marco significativo para esse processo, sobretudo no que compete a descentralização das empresas e consequentemente de seu comércio. Uma característica notável desta descentralização é a criação de lojas virtuais online, que necessariamente não necessitam de um espaço físico para seu funcionamento e oferece a possibilidade de aquisição de produtos e serviços com apenas um clique.

De tal forma, a valorização da informação e do conhecimento, por tanto, tem um novo significado que nos traz possibilidades de interação com novos aparatos tecnológicos que aos poucos se tornam essenciais em nossas vidas, nossos trabalhos, nossas novas relações. A internet sobretudo, constitui parcela significativa nas mudanças que representam diversas 
formas de experiência social, pois são utilizadas de diferentes modos em seu cotidiano, adequando-se às necessidades em distintos aspectos sociais, alterando assim o contexto social em todas as suas esferas.

Uma vez que estabelecidas as TICs como responsáveis por mudanças sociais constantes e a Internet como marco significativa nas revoluções tecnológicas, entende-se que se diminuiu a distância nos processos de construção do saber e consequentemente na popularização do saber científico. Neste processo de revolução tecnológica aspectos sociais, costumes, hábitos e formas de se relacionar ganham novo dimensionamento na troca de informações. Isto é refletido, por exemplo, no mundo do trabalho com a descentralização das empresas, a perda de controle do poder Estatal quanto ao fluxo de informações, no que se refere a esfera midiática, nas formas de manifestações sociais e nos usos políticos da comunicação, com novos espaços de fala e debates, entre tantas e tantas manifestações que são também extensões das relações presenciais.

Sendo assim, novas sociabilidades indicam que o saber não pertence unicamente a uma instituição e não se define por apenas um parâmetro a ser transmitido e até mesmo ressignificado. A sociedade da informação hoje estabelecida é constantemente mutável e dinâmica, influenciando diretamente no desenvolvimento das sociedades contemporâneas. Faz-se por tanto, necessário discutir a aplicação destes fenômenos continuamente.

\subsection{Informação, Comunicação e Conhecimento}

$\mathrm{O}$ atual contexto em que vivemos nos propicia a vida simultaneamente a formas acentuadas de comunicação via aparatos tecnológicos, os processos de informação tornam-se diante deste contexto, extremamente valorizados. Porém, nem sempre a informação se transforma em conhecimento. Não se trata, portanto, de um processo automático e muito menos de um processo que não exija diferenciação. Segundo Marcondes Filho, a informação é:

Aquilo que antes era apenas um "ruído", uma "irritação", pode ser alvo da minha atenção em relação ao outro [...]. Qualquer coisa que esteja ao meu redor só passa a existir no momento em que eu me voltar a ela. Dessa maneira, a percepção de algo absolutamente subordinado à minha relação com as coisas, e não com o mundo em geral. Eu transformo sinais em informação quando me volto a eles, quando lhes dou atenção, quando lhes concedo minha curiosidade ou minha preocupação (MARCONDES FILHO, 2009, p. 87).

De acordo com o autor, a partir do momento em que algo é exposto, torna-se informação quando desperta o interesse. Num contexto atual, da "era da informação", são 
inúmeras as informações bem como fluxos por meio da Internet, das mais diferentes formas e formatos, mas que só se consolidam como informação quando captura o interesse do indivíduo. Antes disso, são meras sinalizações. Marcondes Filho diz que:

Um jornal não contém informações, ele contém notícias, comentários, resenhas, receitas de bolo, horóscopos, previsões futebolísticas, mas não informações. Quem decide se aquilo que está lá é informação ou não sou eu: é informação somente a partir do momento em que alguma dessas coisas me interessar (MARCONDES FILHO, 2008, p. 16).

Então, surge a questão sobre como se daria a possibilidade de absorção de todos os conteúdos presentes. Uma vez que os indivíduos buscam diferentes assuntos, de acordo com diferentes especificidades de interesse e que a maneira como estes são formatados podem ou não a vir se tornar interesse e consequentemente informação.

O processo de comunicação engloba a recepção da fala do outro, a presença do outro e o produto do outro a fim de uma transformação interna (MARCONDES FILHO, 2008). Isto é algo que acontece de forma menos estruturada do ponto de vista técnico, uma vez que as relações sociais e pessoais são bem mais complexas. De forma que cada informação é recebida de forma diferente, assim como sua absorção se dá em níveis e tempos distintos para cada sujeito social.

Diante desta perspectiva entendemos que não há uma comunicação plena ou absoluta, entendida e interpretada por todos de forma uniforme. Ferreira nos aponta que:

[...] a comunicação é um processo adaptativo onde o indivíduo recebe informações do meio processa-as e dá um retorno (feedback). Esse retorno busca uma resposta correta no sentido de buscar o equilíbrio (homeostase) nos seus vínculos com o mundo e nas relações com os outros indivíduos. Por isso, a comunicação tem um aspecto de conteúdo e um aspecto de relação: Comunicar não significa apenas informar conteúdos, mas interagir e dessa maneira é necessário compreender o nível de metacomunicação: os processos de enunciações não-verbais (gestos, olhares, entonações de voz, metáforas etc.) (FERREIRA, 2009, p. 52-53).

O conhecimento no que se refere Edgar Morin, institui um caráter de multiplicidade, diverso, impossível de ser definido em apenas um conceito, ideia ou teoria, compreendendo várias perspectivas. $\mathrm{O}$ autor aponta que:

Por outro lado, todo conhecimento comporta necessariamente: a) uma competência (aptidão para produzir conhecimentos); b) uma atividade cognitiva (cognição), realizando-se em função de competência; c) um saber (resultante de atividades) (2015, p. 18). 
O uso do termo conhecimento diante desta perspectiva é portanto um fenômeno multidimensional, ao mesmo tempo em que é também físico, biológico, cerebral, mental, psicológico, cultural e social. Há uma complexidade na descrição do conhecimento, uma vez que o mesmo envolve processos de inerência, separação e comunicação, intrinsecamente ligados no processo de formulação do saber humano. Morin complementa ainda dizendo que:

\begin{abstract}
Mais do que qualquer outro conhecimento, o humano pressupõe inerência, separação e comunicação. A inerência implica pertencer a um mesmo mundo; o conhecimento dos fenômenos vivos pressupõe a filiação biológica; o conhecimento dos fenômenos culturais pressupõe a filiação a uma cultura. Sem inerência, há separação absoluta, logo nenhuma comunicação possível. Contudo, nessa inerência, há necessariamente separação entre o cognoscente e o cognoscível, ou seja, uma dualidade prévia insuportável. [...] Há, também, entre os indivíduos de uma mesma sociedade, uma relação inerência/separação/comunicação que permite não somente o conhecimento mútuo, mas também, a partilha, a troca a verificação dos conhecimentos. De maneira ainda mais surpreendente, a separação /comunicação está no interior do ser cognoscente e é anterior ao próprio conhecimento (MORIN, 2015, p. 226-227).
\end{abstract}

Para que haja de fato inerência, se faz necessária a permanência no mesmo mundo, conhecendo também os fenômenos biológicos e sociais. A separação é referente ao cognoscente e cognoscível, correspondentes a autonomia do processo de construção do conhecimento, relativo ao que é passível de ser conhecido. Em meio a todos estes aspectos está, como já dito anteriormente, a comunicação. Uma peça de suma importância no processo de formulação do conhecimento.

Nem todo conteúdo se transforma em informação, nem toda a informação portanto resulta em comunicação. Assim como nem toda comunicação se transforma em conhecimento. Considerando todos os aspectos mencionados neste capítulo e no anterior, nos propomos então a discutir de que forma os processos de comunicação se transformam em informação, de que forma a informação se traduz em conhecimento e paralelo a isto, como o uso das TICs, em meio a um contexto de desigualdade social condiciona o letramento científico. Para tal, utilizamos como locus de nossa pesquisa uma experiência que relaciona os saberes comunicacionais, a educação formal e o uso da ciência, através da Escola Municipal Bola na Rede, situada no bairro de mesmo nome, na Região Metropolitana do Recife.

\title{
3. Considerações Finais
}

Isso se evidencia em função de uma falta de dinamicidade, de visibilidade e de transparência no poder. Há uma permanência de oligarquias e elites no poder em contraste com o que se tem de ideais democráticos. Bobbio (1986) diz que poderes invisíveis 
corrompem a democracia, assim como a existência de grupos de poder que se sucedem mediante a eleições livres parecem ser a única forma concreta de atuação democrática.

Mas questiona-se até onde vai a representação de interesses de forma geral. Parece aqui, concordando com Bobbio, que há apenas uma forma alternativa de democracia, paralela a concorrência de grupos de elite pelo poder. Não há reconhecimento entre o singular, nem da nação como um todo.

O ideal democrático trata de uma contraproposta às formas vigentes de autocracia, ou seja, questiona diretamente a perspectiva de quem está apto a tomar decisões de cunho coletivo e quais normas determinam esta tomada de decisões. Quanto maior o número deindivíduos aptos a decisões, ainda que de caráter procedimental, mais justas são as formas de participação e consequentemente maior é a transparência. Entretanto, apenas isso não se faz suficiente.

A democracia moderna de bases ocidentais parece ter sua gênese no individualismo do sujeito, proveniente de suas vontades, referenciada nos ideais da Revolução Francesa e demais cartas de direito daí decorrentes. Hoje parece operar em função de vários centros de poder, como uma configuração poliárquica, pluralista. Adota-se a perspectiva de um ideal pós-moderno, caracterizada fundamentalmente pela representação, de constância de interesses de uma nação e não a interesses particulares, de forma a legitimar e controlar as decisões políticas no exercício da prática democrática.

\section{Referências}

BACHELARD, Gaston. A formação do espírito científico: contribuição para uma psicanálise do conhecimento. Rio de Janeiro: Contraponto, 1996.

BARREIRA, César. Ligado na galera, juventude, violência e cidadania na cidade de Fortaleza. Brasília: UNESCO, 1999.

CANCLINI, Néstor García, 2003. Globalizar-se ou defender a identidade: como escapar dessa opção. In: CANCLINI, Néstor García. A Globalização imaginada. São Paulo: Iluminuras, 2003. pp. $19-40$.

CASTELLS, Manuel. A sociedade em Rede. A era da informação: economia, sociedade e cultura; v.1. São Paulo: Paz e Terra, 1999.

de Janeiro: Zahar, 2003.

Galáxia da internet: reflexões sobre a internet, negócios e sociedade. Rio

CASTELLS, Manuel; CARDOSO, Gustavo (org.). A Sociedade em Rede: do conhecimento à ação política. Conferência. Belém (Por): Imprensa Nacional, 2005. 
Chauí MS. Convite à filosofia. 3a ed. São Paulo: Ática; 1995.

Chaui, Marilena. Cultura e democracia . En: Crítica y emancipación : Revista latinoamericana de Ciencias Sociales. Año 1, no. 1 (jun. 2008- ). Buenos Aires : CLACSO, 2008- . -- ISSN 1999-8104. Disponível em:

http://bibliotecavirtual.clacso.org.ar/ar/libros/secret/CyE/cye3S2a.pdf (acesso em 20/01/2015).

GIDDENS, Anthony (2000). Mundo em descontrole. Rio de Janeiro, Record. HABERMAS, Jürgen (1989). Consciência moral e agir comunicativo. Rio de Janeiro, Tempo Brasileiro.

HALL, Stuart. A identidade cultural na pós-modernidade. Tradução: Tomaz Tadeu da Silva, Guaracira Lopes Louro. 11. ed. Rio de Janeiro: DP\&A Editora, 2006.

LIMA, Ivanice, \& SANTOS, Maria Salett Tauk. "Rádio comunitária construindo o capital social: mulheres rurais na produção radiofônica." Comunicação \& Educação [Online], 17.1 (2012): 23-30. (Acesso em 29 de Outubro de 2014).

LÉVY, Pierre. Cibercultura. São Paulo: Ed. 34, 1999.

MATTELART, Armand. A construção Social do direito à Comunicação como parte integrante dos direitos humanos. Intercom - Revista Brasileira de Ciências da Comunicação. São Paulo, v.32, n.1, p. 33-50, jan./jun. 2009.

MARCONDES FILHO, Ciro. Para entender a comunicação: contatos antecipados com a nova teoria. São Paulo: Ed. Paulus, 2008. (Coleção temas de Comunicação).

MILLS, C. Wright. Sobre o artesanato intelectual e outros ensaios. trad. Maria Luiza X. de A. Borges. Rio de Janeiro: Ed. ZAHAR, 2009.

MINAYO, Maria Cecília de Souza. Ciência, técnica e arte: o desafio da pesquisa social in: Pesquisa Social: Teoria, Método e Criatividade. Orgs. Suely Ferrereira Deslandes; Otávio Cruz Neto; Romeu Gosmes; Maria Cecília de Souza Minayo. Petrópolis/RJ: Vozes, 1994.

MORIN, Edgar. O método 3: conhecimento do conhecimento. Trad. Juremir Machado da Silva. 5a edição. Porto Alegre: Ed. Sulina, 2015.

PERUZZO, Cicilia (2005). Internet e democracia comunicacional: entre os entraves, utopias e o direito à comunicação. in MELO, José Marques de.

SABBATINI, M. Alfabetização e Cultura Científica: conceitos convergentes? Comunicação \& Ciência, volume 1, n. 1, dez 2004. Disponível em: www. jornalismocientífico.com.br.

SATHLER, Luciano (2005). Direitos à comunicação na sociedade da informação. São Bernardo do Campo, Umesp.

SABBATINI, M. Novos modelos da percepção pública da ciência e da tecnologia: do modelo contextual de comunicação científica aos processos de participação social. XXVII Congresso Brasileiro de Ciências da Comunicação, 2004, Porto Alegre. 
SPENILLO, Giuseppa. M. D. "Direito Humano a Comunicação" In Direito à Comunicação: uma formulação contemporânea de exigências de mudanças nas estruturas coletivas de comunicação e informação. Contribuições para uma análise sociogenesiológica e configuracional da articulação CRIS Brasil. CPDA - UFRRJ. Rio de Janeiro, 2008.

SUZINA, Ana Cristina. A contribuição dos meios de comunicação populares e alternativos ao desenvolvimento da democracia e da cidadania no Brasil. Anais do V Congresso da Compolítica, 2013.

UNESCO. Comissão Internacional para o Estudo dos Problemas da comunicação. (1983). Um mundo e muitas vozes; comunicação e informação na nossa época. Rio de Janeiro, Editora da Fundação Getúlio Vargas.

VOGT, C. Ciência, comunicação e cultura científica. In: Vogt, C.(org). Cultura científica: desafios. SP: Universidade de São Paulo, Fapesp, 2006. p.19-26. 